Hammersmith Hospital, London, have introduced the method for the differentiation of congenital muscular dystrophy and non-neuromuscular cases of hypotonia. ( $\mathrm{J}$ Child Neurol $1987 ; \underline{2}$ : 205$)$.

\title{
CONGENITAL MYOTONIC DYSTROPHY AND PLEURAL EFFUSION
}

Two infants with congenital myotonic dystrophy complicated by pleural effusions and hydrops fetalis are reported from the Valley Children's Hospital, Fresno, CA, and the Royal Alexandra Hospitals, University of Alberta, Edmonton, Alberta, Canada. The mothers had myotonic dystrophy diagnosed at or after the delivery. The pregnancies were complicated by polyhydramnios, and the infants were delivered by cesarean section because of breech presentation. Infant 1 was areflexic, profoundly hypotonic, failed to breathe spontaneously, and died at 3 days of age. Muscle biopsy at autopsy revealed extreme muscle immaturity with poor type I/II fiber differentiation, type I and type IIc fibers, and central nucleation. Infant 2 died 25 min after delivery despite aggressive resuscitation. The authors cite 6 other cases of congenital myotonic dystrophy with fetal hydrops and 2 with pleural effusions. Fetal hydrops may obscure the diagnosis, especially if the mother is asymptomatic. (Curr CJR et al. Hydrops and pleural effusions in congenital myotonic dystrophy. J Pediatr Sept 1988; $113: 555-557$ ).

\begin{abstract}
COMMENT. Chromosomal defects, cardiac abnormalities, and genetic syndromes are described with fetal hydrops but congenital myotonic dystrophy has been associated infrequently. When a mother is known to have myotonic dystrophy, the fetus should be monitored for abnormal breathing patterns and pleural effusions. A hypotonic infant born with pleural effusion or hydrops should alert the examiner to check for myotonia in the mother. (See Ped Neur Briefs Sept $1987 ; \underline{1}: 29-30)$.
\end{abstract}

\section{NEONATAL CEREBRO-VASCULAR DISORDERS}

\section{NEONATAL STROKE OUTCOME}

The clinical outcome of 17 children, 1 to 11 years of age, who experienced cerebral artery infarctions as neonates has been studied in the Depts of Pediatrics and Neurology, Univ of Kentucky Med Center, Lexington, Kentucky. The left middle cerebral artery (MCA) was involved in 9 (53\%) and the right MCA in $5(30 \%)$. Fourteen $(82 \%)$ who developed neonatal seizures became seizure free and neurologically normal within the first year and anticonvulsants were discontinued. Three patients had recurrence of seizures after 1 to 8 years and anticonvulsants were renewed. Eleven patients (65\%) have normal neurologic development but one of 2 attending school has cognitive 
deficits. (Stan SK, Baumann, RJ. Outcome of neonatal strokes.

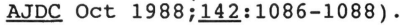

COMMENT. The authors conclude that infants with a unilateral arterial stroke generally have a favorable prognosis initially but require long-term follow up for possible recurrence of seizures and development of learning disabilities. Comparing these results with a previous report of neonatal stroke (See Ped Neur Briefs Aug $1988 ; 2: 63-64)$, the increased prevalence of left middle cerebral artery infarction and the frequent complication of neonatal seizures are in agreement, but the recovery of neurologic function within 1 year is in contrast to a persistent hemiparesis in 668 of patients examined at $1-4$ years of age.

\section{INFECTIOUS DISEASE}

\section{BACTEREMIA AND FEBRILE SEIZURES}

The frequency of occult bacteremia among children treated as outpatients for simple febrile seizures has been investigated in the Dept of Pediatrics, Univ of Maryland School of Medicine and St. Agnes Hospital, Baltimore, MD. Patients seen with fever but without a history of febrile seizures had blood cultures performed more frequently than those with a history of seizures. Of 115 patients with febrile seizures, 93 had blood cultures of which $5(5.4 \%)$ were positive, all for Streptococcus pneumoniae. Follow-up blood cultures on return to the ER were negative. Three of the 5 had been treated with amoxicillin suspension for otitis media and 2 had not received antibiotics. There was no significant difference in the occurrence of positive blood cultures in those with and without a history of febrile convulsions. The leukocyte count was the most valuable predictor of bacteremia. A temperghture less than $39^{\circ} \mathrm{C}$ and leukocyte count less than $15 \times 10^{2} / L$ were predictive of a negative blood culture. Of those with a gositive culture, the mean leukocyte count was $20.9 \times 10 / \mathrm{L}$ and the mean temperature was $40.2^{\circ} \mathrm{C}$. Patients admitted to the hospital because of complications (e.g. meningitis, status epilepticus, facial cellulitis, and reactions to DPT vaccine) were excluded from the analysis. The authors recommend that the indications for blood culture are the same in patients with fever, with or without seizures. (Chamberlain JM, Gorman RL. Occult bacteremia in children with simple febrile seizures. AJDC Oct

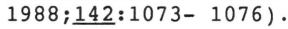

COMMENT. It is interesting that the American Academy of Pediairics Consensus statement from 1980 regarding the workup for febrile seizures did not include mention of blood culture. The authors of the paper reviewed here point out that patients with fever complicated by seizure 